\title{
Vasospastic angina - myocarditis imitation: a case report
}

\section{Blanka Glavaš \\ Konja*, \\ ㄴ) Vlatka Rešković \\ Lukšić, \\ (1)Joško Bulum, \\ OMartina Lovrić \\ Benčić, \\ CMarija Mance, \\ ZZvonimir Ostojić, \\ -Lada Bradić, \\ Davor Radić, \\ - TTea Šimonček, \\ (1) Jadranka Šeparović \\ Hanževački}

University of Zagreb School of Medicine, University Hospital Centre Zagreb, Zagreb, Croatia
RECEIVED:

February 28, 2019

ACCEPTED:

March 24, 2019

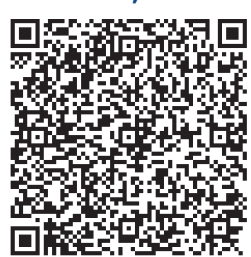

KEYWORDS: vasospastic angina, variant angina, myocarditis, diagnosis.

CITATION: Cardiol Croat. 2019;14(3-4):53-4. | https://doi.org/10.15836/ccar2019.53

*ADDRESS FOR CORRESPONDENCE: Branka Glavaš Konja, Klinički bolnički centar Zagreb, Kišpatićeva 12, HR10000 Zagreb, Croatia. / Phone: +385-1-2367-490 / E-mail: blanka.glavas@gmail.com

ORCID: Blanka Glavaš Konja, http://orcid.org/0000-0003-1134-4856 • Vlatka Rešković Lukšić, http://orcid.org/0000-0002-4721-3236 Joško Bulum, http://orcid.org/0000-0002-1482-6503 • Martina Lovrić Benčić, http://orcid.org/0000-0001-8446-6120

Marija Mance, http://orcid.org/0000-0003-1542-2890 • Zvonimir Ostojić, http://orcid.org/0000-0003-1762-9270

Lada Bradić, https://orcid.org/0000-0001-8296-699X • Davor Radić, https://orcid.org/0000-0002-9132-1568

Tea Šimonček, https://orcid.org/0000-0002-6755-453X • Jadranka Šeparović Hanževački, http://orcid.org/0000-0002-3437-6407

||||||||||||||||||||||||||||||||||||||||||||||||||||||||||||||||||||||||||||||||||||||||||||||||||||||||||||||||||||||||||||||||

Case report: 45-year-old woman was hospitalized for severe chest pain. Her medical problem began four months earlier. ECG and echocardiographic findings were normal. Stress test was stopped because of chest pain at 8 METs. At the time of two-minute chest pain, the ECG recorded intermittent left branch block (Figure 1). The 24h Holter ECG showed the frequency dependent left bundle branch block (LBBB) but no chest pain episode. MSCT coronary artery detected normal coronary arteries. Cardiac MR was suggestive to myocarditis. Troponin and inflammatory parameters during the four months of follow-up remained normal. Considering the persistence of symptoms, coronary angiography was performed showing normal epicardial arteries. During angiography, the patient experienced chest pain at the time of right coronary artery (RCA) probing, and coronary artery spasm of the proximal RCA was obvious at the time (Figure 2). After the nitroglycerin bolus application, spasm disappears (Figure 3) and chest pain released. During the coronary angiography there was no ST-segment elevation, nor intermittent LBBB. Vasospastic angina has been diagnosed. The patient was further treated with calcium antagonists and long-acting nitrates resulting in clinical improvement.

Discussion: Early diagnosis of variant angina is crucial to avoid major cardiac events ${ }^{1}$. In the case of large coronary artery spasm, the ECG can show impermanent ST elevation. LBBB was observed temporarily in our patient during stress test concomitant with chest pain but not in the $24 \mathrm{~h}$ Holter ECG recording. Coronary vasospasm and myocarditis are both recognized mimics of ST-segment elevation myocardial infarction with normal coronary arteries. The occurrence of both pathologies in the same patient has rarely been described ${ }^{2}$. Our patient had no troponin increase recorded, and no inflammatory

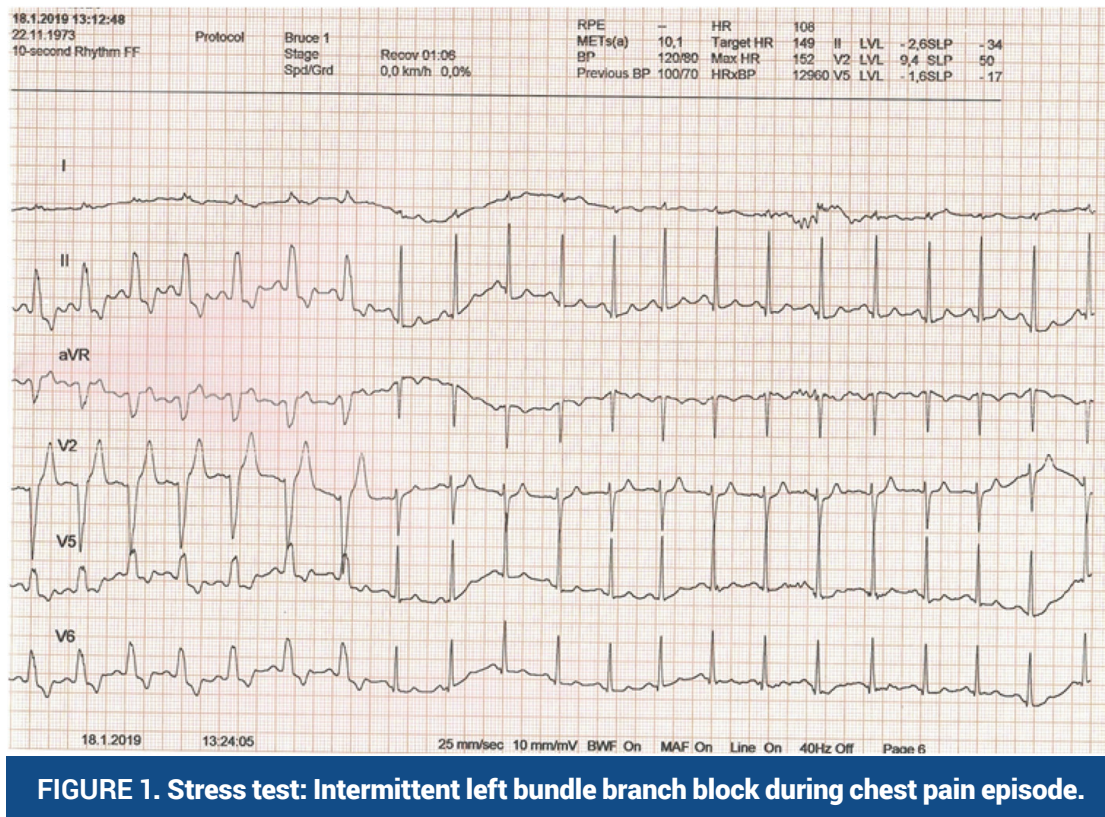



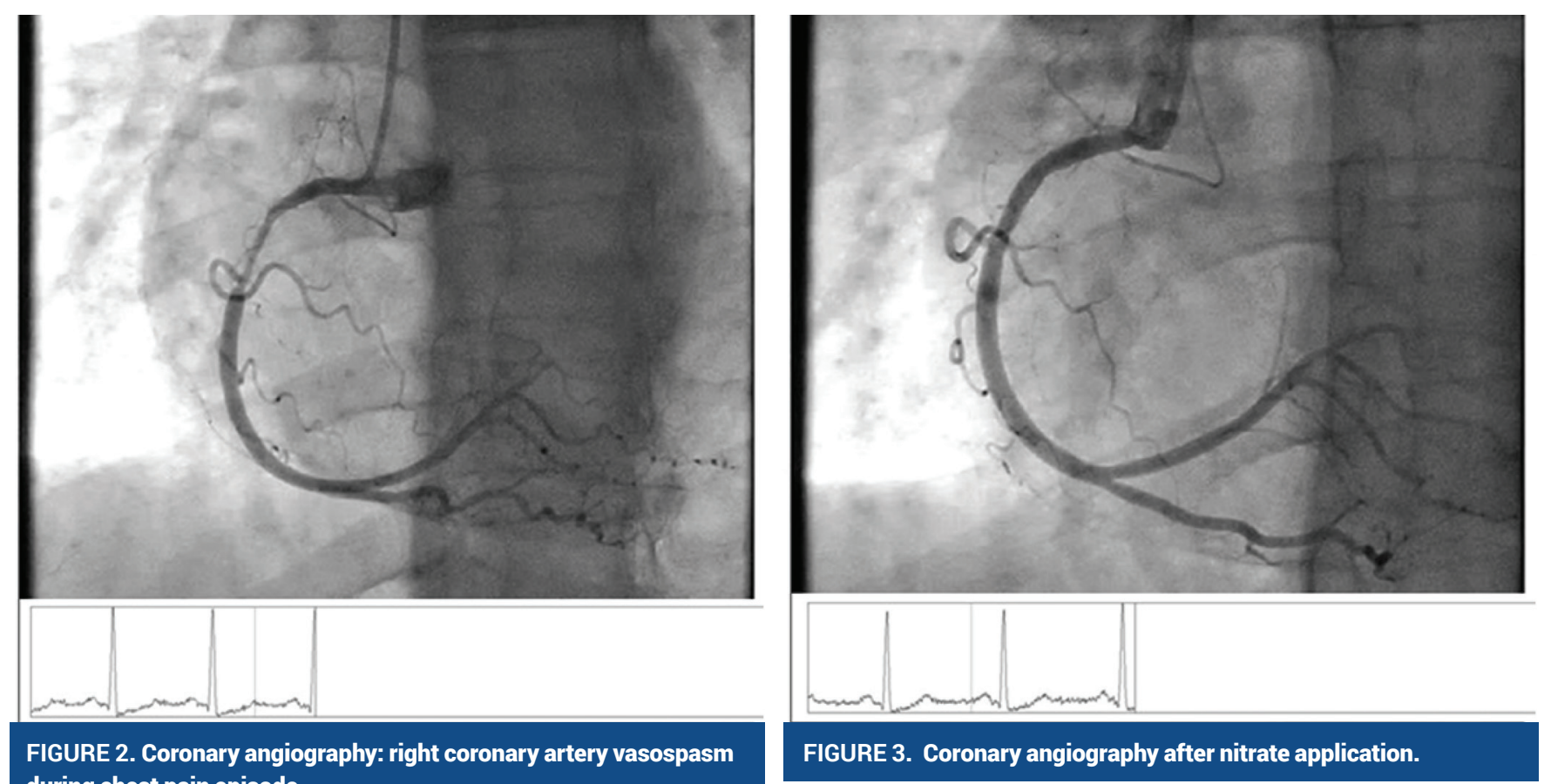

FIGURE 2. Coronary angiography: right coronary artery vasospasm during chest pain episode.

parameters. It is important to note that the diagnostic sensitivity and specificity of the CMR for pericarditis is under $100 \%{ }^{3}$. The case confirms the complexity of vasospastic angina diagnosis, and the importance of understanding the diagnostic imaging limitations.

1. Lanza GA, Crea F. Vasospastic angina. E-Journal of Cardiology Practice. 2003. Vol. 2, No 9 - 11 Nov 2003.

2. Rowe MK, Rutherford M, Kostner K. An unusual cause of ST elevation: Coronary vasospasm complicating acute myocarditis - A case report and review of literature. J Clin Prev Cardiol. 2016:5(4):146-8. https://doi.org/10.4103/2250-3528.192699

3. Friedrich MG, Marcotte F.Cardiac magnetic resonance assessment of myocarditis. Circ Cardiovasc Imaging. 2013 Sep;6(5):833-9. https://doi.org/10.1161/CIRCIMAGING.113.000416 